\title{
Effect of annealing and UV-radiation time over micropore architecture of self-assembled block copolymer thin film
}

\author{
G. del C. Pizarro ${ }^{1 *}$, O. G. Marambio ${ }^{1}$, M. Jeria-Orell ${ }^{1}$, C. M. González-Henríquez ${ }^{1}$, \\ M. Sarabia-Vallejos ${ }^{2}$, K. E. Geckeler ${ }^{3,4}$ \\ ${ }^{1}$ Departamento de Química, Universidad Tecnológica Metropolitana. J. P. Alessandri, 1242 Santiago, Chile \\ ${ }^{2}$ Facultad de Física, Pontificia Universidad Católica de Chile, Vicuña Mackenna, 4860 Santiago, Chile \\ ${ }^{3}$ Laboratory of Applied Macromolecular Chemistry, School of Materials Science and Engineering, Gwangju Institute of \\ Science and Technology (GIST), 500-712 Gwangju, South Korea \\ ${ }^{4}$ Department of Nanobio Materials and Electronics (WCU), Gwangju Institute of Science and Technology (GIST), \\ 500-712Gwangju, South Korea
}

Received 13 October 2014; accepted in revised form 25 December 2014

\begin{abstract}
Block copolymers have been recognized as versatile materials to prepare nanoporous polymer films or membranes, but their potential has not been completely explored. This study focuses on the formation and characterization of nanoporous polymer films based on poly(styrene)-block-(methylmethacrylate/methacrylic acid); (PS- $b$-MMA/MAA) were obtained through atom transfer radical polymerization (ATRP), by using two different protocols: annealing and annealingirradiation; for improving the formation of microporous surface. The composition, crystallinity and structural order of the films were studied by Raman spectroscopy. The film polymer thickness was obtained through very high resolution ellipsometry (VHRE). Finally, atomic force microcopy (AFM) and scanning electron microscopy (SEM) techniques were used to detect changes in the porous-structure. These results show that the morphological properties of the block copolymer were affected via the modification of two variables, UV-radiation time and annealing. SEM and AFM micrographs showed that the morphology exhibit a porous ordered structure. Contact angle measurement suggests additional interactions between hydrophilic functional groups that influence the film wettability.
\end{abstract}

Keywords: polymer membranes, self-assembled diblock copolymers, thin films, irradiation, annealing

\section{Introduction}

Thin films prepared from different materials have recently been interesting for many fields such as electronic semiconductor devices, optical coatings, and pharmaceuticals drug delivery [1,2]. An increasing interest has aroused about preparing polymeric materials with ordered microstructures. The growing demand for films or membranes with controlled nanostructures for different applications, for example molecular electronics [3], optical devices [4], biological [5] and chemical sensors [6], including water desalination and other alternative technolo- gies, have brought new perspectives to membrane science.

Structural changes at molecular level, in combination with surface chemistry, allow the manipulation of material intrinsic properties for some specific applications [7]. A large number of methods has been used to produce ordered periodic arrays of various materials with sizes from nanometer to micrometer such as conventional lithography, soft lithography $[8,9]$, etc.

The last decade, some inexpensive non-lithographical techniques such as phase separation [10], dewet-

${ }^{*}$ Corresponding author, e-mail: pizarroguadalupe048@gmail.com (C) BME-PT 
ting [11], air bubble [12] and convection [13] provide other routes for patterning polymeric materials.

Furthermore, the properties of amphiphilic diblock copolymers produce great interest in industrial fields due to their micro- or macro- phase-separated morphologies. Phase separation in thin block copolymer film can be lead to various morphologies such as islands, bicontinuous structure, etc.; this is a new way of patterning polymeric materials through controlling phase separation morphologies of thin polymer films varying the block domain length [14]. These self-assembled domains are essentially monodisperse, with nanometer dimensions, in which its morphology and sizes are controlled by altering each block length and the total molecular mass [15].

The thermodynamic reasons for block copolymer patterns have been the topic of several classical papers in the field. For example, Guarini et al. [16] used UV light (185 and $254 \mathrm{~nm}$ ) to etch methyl methacrylate blocks of PS- $b$-MMA copolymers, followed by removal in acetic acid to form a porous structure to yield nanoporous membranes. Yang et al., [17] prepared thin films of poly(styrene- $b$-methyl methacrylate) and poly(methyl methacrylate) on silicon oxide substrates to give an ordered morphology. Phillips and co-workers [18, 19] and Jackson and Hillmyer [20] prepared dense thin films of poly (styrene- $b$-polylacticide) on the top of a microporous support treated with UV to improve adhesion and promote cross-linking. The lactic acid block domain was etched by immersion in methanol/water and $\mathrm{NaOH}$ to form pores. Development of nanoporous templates from block copolymers for optoelectronics and other applications is a fast-growing field. Recent reviews with a large number of examples are available. [21-23].

This work focuses on the microporous structured films formation prepared by solvent casting with annealing above the glass temperature and UV irradiation using the self-assembled amphiphilic PS- $b$ MMA/MAA block copolymer synthesized by ATRP [24]. With the analysis realized in this work it was possible to investigate the role of physical and chemical interactions between PMAA segments, increasing film surface hydrophilicity, due to hydrogen bonding generated between these chains. Also, annealing process produced an ordering change in the arrangement of the functional groups.

On the other hand, it is known that polystyrene and polymethyl methacrylate are amorphous thermo- plastics materials, these fact implies that physical properties are also influenced by macromolecular orientation caused by shaping, resulting from the presence of special interactions between these chains. Last, but not least, the quality is influenced by additives, for example plasticizers, UV light and heat stabilizers, among others. Low fraction of PMAA exposed to ambient air absorb some \% moisture, water acts as a plasticizer, a decreasing $T_{\mathrm{g}}$ is expected when the amount of absorbed water increases, affecting the spatial conformation of the macromolecule. Also, annealing process at $120^{\circ} \mathrm{C}$, above the glass transition temperature $\left(65^{\circ} \mathrm{C}\right)$ produces polymers that have not yet reached their crystallinity, forming crystals when molecule mobility is sufficiently high (polymer mobility increases with temperature). In addition, possible hydrogen bonding generated between carboxylic acid groups affects polymer molecular arrangement, favors certain structural ordering into the system, this behavior was observed by Raman spectroscopy.

The films were characterized by FT-IR and Raman spectroscopy, thermogravimetric analysis (TGA), differential scanning calorimetry (DSC), UV-Vis spectroscopy, fluorescence, scanning electron microscopy (SEM), potentiodynamic electrochemical measurement, transmission electron microscopy (TEM) and atomic force microcopy (AFM) techniques.

According to preliminary studies, two different series of thin films were prepared: the first with annealing at $120^{\circ} \mathrm{C}$ for 2 hours and the second with annealing and subsequent UV irradiation at $254 \mathrm{~nm}$ for 2, 4, 6 and $8 \mathrm{~h}$. The time series was used to understand the porosity change at surface level over time. The thin films thickness was determined using very high resolution ellipsometry (VHRE). Raman spectroscopy was used to study changes in crystallinity and possible polymer chains ordering into the system. Atomic force microscopy (AFM) and scanning electronic microscopy (SEM) were performed to detect morphology changes at surface level and to determine pore dimensions (shape, depth and diameter).

\section{Experimental section \\ 2.1. Materials}

Styrene (purchased from Sigma-Aldrich chemicals, CHEMIE, Germany) was washed with $5 \%$ aqueous $\mathrm{NaOH}$ to remove inhibitor and distilled under reduced pressure before use. Methylmethacrylate 
(MMA) (obtained from Merck-Schuchardt Chemicals, Germany) was purified by distillation under reduced pressure. Benzoyl peroxide (BPO) (MerckSchuchardt, with $25 \% \mathrm{H}_{2} \mathrm{O}$, CHEMIE, Germany) was used as received. Copper(I) bromide (Aldrich, 98\%) was purified by stirring overnight over $\mathrm{CH}_{3} \mathrm{COOH}$ at room temperature, followed by washing with ethanol and diethyl ether prior to drying at $50^{\circ} \mathrm{C}$ under vacuum for 1 day. 2, 2'-Bipyridyl (Sigma-Aldrich, 99\%) was used as received.

\subsection{Methods and equipment}

The number-average $\left(M_{\mathrm{n}}\right)$ and weight-average $\left(M_{\mathrm{w}}\right)$ molecular weights and the molecular weight distribution (polydispersity, $M_{\mathrm{w}} / M_{\mathrm{n}}$ ) of polymers were determined using size exclusion chromatography (SEC) under the following conditions: WATERS 600E instrument equipped with UV and RI detectors using THF as solvent (flow rate: $1.0 \mathrm{~mL} / \mathrm{min}$ ). The samples were measured at $30^{\circ} \mathrm{C}$ with a concentration of $6 \mathrm{mg} / \mathrm{mL}$, calibration was performed using polystyrene.

Infrared spectra were measured on a Bruker Vector 22 FT-IR spectrometer (Bruker Optics GmbH, Inc., Ettlingen, Germany) using OPUS 3.14 software to control the measurements. In previous work [24], this polymeric structure was characterized by ${ }^{1} \mathrm{H}$ and ${ }^{13} \mathrm{C}$ NMR analysis studied on a Bruker $400 \mathrm{MHz}$ spectrometer using $\mathrm{CDCl}_{3}$ the solvent. The structural chemical composition of copolymer films were characterized using Raman spectroscopy with a LabRam 010 instrument from ISA equipped with a $5.5 \mathrm{~mW}, 632.8 \mathrm{~nm} \mathrm{He}-\mathrm{Ne}$ laser without a filter. The Raman microscope uses back-scattering geometry, in where incident beam is linearly polarized at a 500:1 ratio. The microscope objective lens was an Olympus Mplan 100× (numerical aperture 0.9).

TG and DSC thermograms were recorded under nitrogen atmosphere. Studies of thermal stability were performed using a Star System 1 thermogravimetric analyzer (TGA) with a heating rate of $10^{\circ} \mathrm{C} / \mathrm{min}$. DSC measurements were performed with a Mettler Toledo Star System 822e in order to determine the copolymer glass transition temperature ( $T_{\mathrm{g}}$ ). The $T_{\mathrm{g}}$ was measured with $10^{\circ} \mathrm{C} / \mathrm{min}$ heating rate; to eliminate the effect of thermal history on the phase transitions, all samples were heated to $150^{\circ} \mathrm{C}$, held that temperature for $5 \mathrm{~min}$ and then cooled to $30^{\circ} \mathrm{C}$.
The absorption spectra of PS- $b$-MMA/MAA were recorded at $25^{\circ} \mathrm{C}$ between $250-400 \mathrm{~nm}$ using a Perkin Elmer Lambda 35 spectrophotometer, intensity of $3.5 \mathrm{~mW} / \mathrm{cm}^{2}$ since $365 \mathrm{~nm}$. Photoluminescence (PL) spectra of solid samples were recorded at room temperature with a Perkin Elmer L55 spectrofluorimeter, using an excitation wavelength of $320 \mathrm{~nm}$. Both analyses were recorded using THF as solvent for the copolymer dissolution.

Cyclic voltammetry was carried out using an Aut 302 Ecochimie Autolab potentiostat/galvanostat recorded in DMF (ca $1.0 \cdot 10^{-3} \mathrm{~mol} / \mathrm{L}$ ) under nitrogen atmosphere with TBAP (ca $0.1 \mathrm{~mol} / \mathrm{L}$ ) using threeelectrode cells. A hanging-drop mercury electrode (HDME) was used as working electrode, a platinum wire as auxiliary electrode, and saturated calomel (SCE) as reference electrode. The electrolyte support was a solution of $0.1 \mathrm{M}$ (dissolved in DMF) $\mathrm{LiCl}$. The experiments were carried out under nitrogen atmosphere at room temperature for the entire range of sweep rates. The DMF solvent was used without previous treatment.

The polymer morphology was examined using a SEM model LEO 1420VP with $100 \mu \mathrm{A}$ beam current and working distance of $12-14 \mathrm{~mm}$. The microscope was operated at high vacuum (system vacuum $\sim 10^{-6}$ mbar and chamber $10^{-3}$ mbar). TEM observations were performed using a JEOL JEM $1200 \mathrm{EX}$ instrument operated at $120 \mathrm{kV}$, with a point resolution of approx. $4 \AA$. These images were taken by placing a drop of block copolymer dissolved in THF over carbon-coated copper grid. The equipment was operated at high vacuum $\left(\sim 10^{-5}\right.$ mbar $)$. Also, block copolymers surface characterization was performed using an AFM Digital Instruments NanoScope IIIA Series in 'tapping' mode. The polymer powder was dissolved in THF and cast on glass slides using spin coating technique with rotation frequency of $500 \mathrm{rpm}$ for approximately $10 \mathrm{~s}$ and $1600 \mathrm{rpm}$ for approximately $10 \mathrm{~s}$. Contact angle was corroborated by sample roughness test using AFM technique.

Very High Resolution Ellipsometry (VHRE) with single wavelength laser (He-Ne, $632.8 \mathrm{~nm}$ ) in PCSA null configuration was used to determine the film thickness. Laser beam incidence angle was $60.5^{\circ}$ respect to sample normal. The film thicknesses were calculated using the Drude model for single layers with ellipsometric parameters $\Delta$ and $\psi$, which 
are related to the measured polarizer $P\left(\Delta=2 \mathrm{P}+90^{\circ}\right)$ and analyzer $A(A=\psi)$ angles. The refractive index value for poly(methylacrylate) was $n=1.5343$, and polystyrene $n_{\mathrm{PS}}=1.5894$, and for the amphiphilic PS$b$-MMA/MAA block copolymer was used the average of these last ones, $n_{\mathrm{PS}-b \text {-MMA/MAA }}=1.5662$ [25].

\subsection{PS- $b$-MMA/MAA block copolymer}

The PS- $b$-MMA/MAA was synthesized by ATRP using MMA/PS-Br $/ \mathrm{CuBr} / \mathrm{BPy}$, in a molar ratio of $100 / 1 / 1 / 2$, previously published by our research group [24]. The molecular weight and polydispersity were $10.2 \cdot 10^{4} \mathrm{~g} / \mathrm{mol}$ and 1.30 , respectively. The polymerization degree of PS and PMMA were calculated from molecular weight using SEC were $D P_{\mathrm{n}}=699$ for PS and $D P_{\mathrm{n}}=290$ for PMMA. PS- $b$ MMA/MAA was obtained by acidic hydrolysis of methyl ester linkages in the MMA blocks (see Figure 1). According to these results, the ${ }^{1} \mathrm{H}$ NMR spectra of hydrolyzed block copolymer show a $20 \%$ decrease in signal intensity at $3.5-3.6 \mathrm{ppm}\left[-\mathrm{CH}_{3}\right.$ ester protons of the MMA block], which corresponds to the percent hydrolysis of methyl ester, indicating the formation of $\mathrm{COOH}$ groups, given the Poly $\left(\mathrm{S}_{699}\right.$-block- $\left.\mathrm{MMA}_{232} / \mathrm{MAA}_{58}\right)$ block copolymer.

\subsection{Preparation of polymer films}

The PS- $b$-MMA/MAA was dissolved in THF at concentrations of $0.5 \mathrm{mg} / \mathrm{mL}$ at room temperature. Thin films were prepared using silicon wafers $\left(\mathrm{Si}_{(100)}\right)$ $\left.\mathrm{SiO}_{2}\right)$ as substrate by spin-coating $(360 \mathrm{rpm} / 18 \mathrm{~s}$ and $1480 \mathrm{rpm} / 60 \mathrm{~s}$ ). According to this method, a film series were prepared to investigate the effect of irradiation time on surface porosity. One film was annealed at $120^{\circ} \mathrm{C}$ for 2 hours to produce certain molecular arrangement; the second film series were annealed for the same temperature and time. Afterwards these films were exposed to UV light $(254 \mathrm{~nm})$ for 2, 4, 6, and 8 hours.

\section{Results and discussion}

\subsection{Structural studies of the polymeric films: FTIR and Raman analysis}

Molecular structure was confirmed and corroborated by FT-IR and Raman spectroscopy, as shown in Figure 2. The absorption bands (double peak) between 1731 and $1601 \mathrm{~cm}^{-1}$ correspond to both symmetric and asymmetric $\mathrm{C}=\mathrm{O}$ stretching of carboxylic acid carbonyl and ester carbonyl groups, the band at $3446 \mathrm{~cm}^{-1}$ correspond to $\mathrm{OH}-$ stretching of carboxylic acids that usually exist as hydrogen-bonded dimers (see Figure 2 curve a).

The Raman spectra also exhibited a strong peak at $3052-3039 \mathrm{~cm}^{-1}$ assigned to the aromatic protons (C-H stretching in plane bending), at 2952$2900 \mathrm{~cm}^{-1}$ assigned to the alkane (C-H anti-symmetric stretching $-\mathrm{CH}_{3}$ ), and a band of low intensity at $1720 \mathrm{~cm}^{-1}$ assigned to the $\mathrm{C}=\mathrm{O}$ (stretching). This same vibration appears intensely by infrared spectroscopy near $1730 \mathrm{~cm}^{-1}$. The strong bands obtained by Raman spectroscopy at $1602-1583 \mathrm{~cm}^{-1}$ were assigned to $\mathrm{C}=\mathrm{C}$ aromatic (stretching), (see Figure 2 curve b). The band at $1451 \mathrm{~cm}^{-1}$ was assigned to alkenes ( $-\mathrm{CH}_{2}$ bending). The same vibration appears in infrared spectroscopy $\left(1450 \mathrm{~cm}^{-1}\right)$. However, IR shows only the frequency near $1490 \mathrm{~cm}^{-1}$, corresponding to $\mathrm{C}=\mathrm{C}$ stretching of the aromatic ring. The band at $1200-1154 \mathrm{~cm}^{-1}$ was assigned to $\mathrm{C}-\mathrm{O}$ stretching of ester group. A strong signal at $1000 \mathrm{~cm}^{-1}$ was assigned to $\mathrm{C}-\mathrm{C}$ aromatic (stretching), and the band at $619 \mathrm{~cm}^{-1}$ was assigned to $\mathrm{C}-\mathrm{H}$ aromatic (stretching out of plane in opposite direction). Both signals were observed with very low intensity by IR spectroscopy.

\subsection{Thermal analysis}

The thermal decomposition temperature and the value of glass transition temperature $\left(T_{\mathrm{g}}\right)$ of PS- $b$ MMA/MAA was investigated by TGA and DSC, respectively (see Figure 3 ). The TGA curve exhibited slight weight loss approximately $76^{\circ} \mathrm{C}$, with $5 \%$

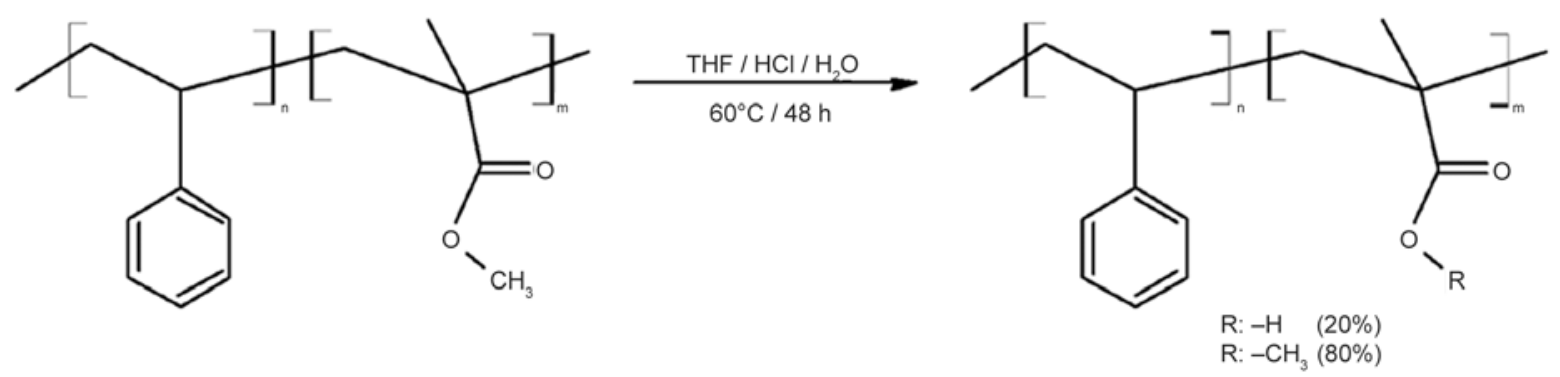

Figure 1. Representation of hydrolysis process for functional hydrophilic microdomains of PS- $b$-MMA/MAA block polymer 


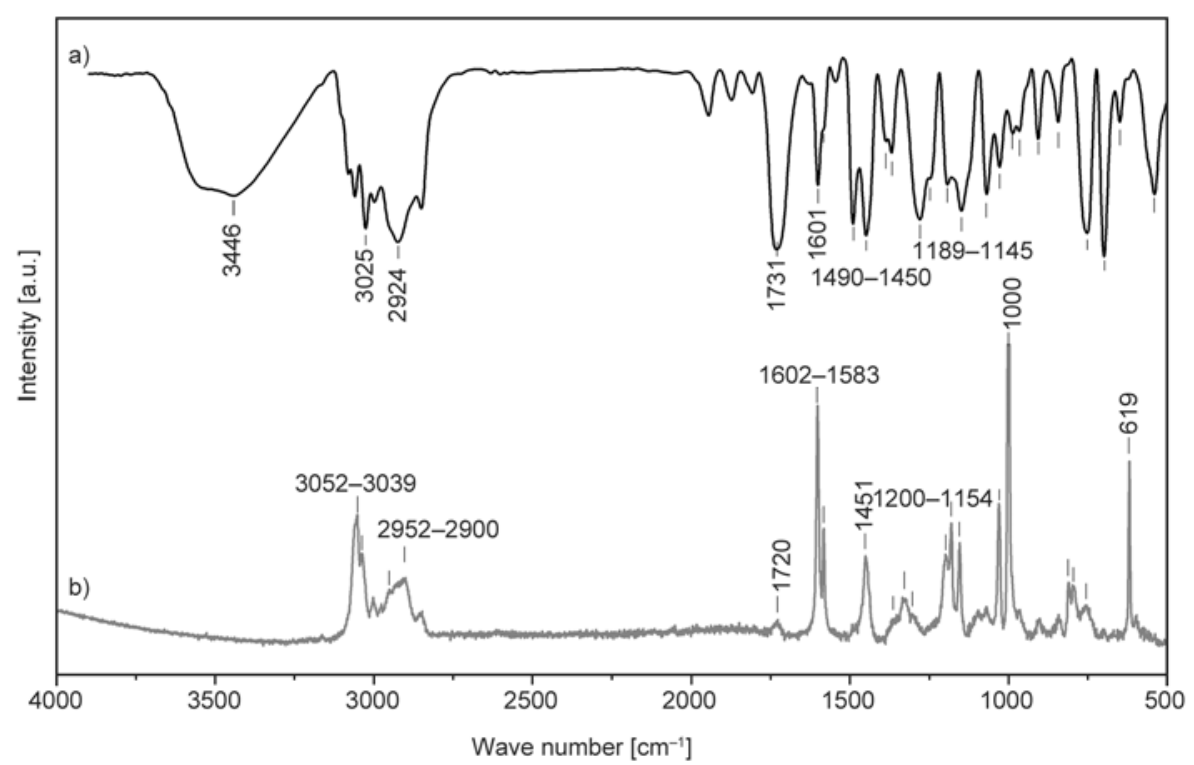

Figure 2. a) FT-IR spectrum and b) Raman spectrum of PS- $b$-MMA/MAA block copolymer films

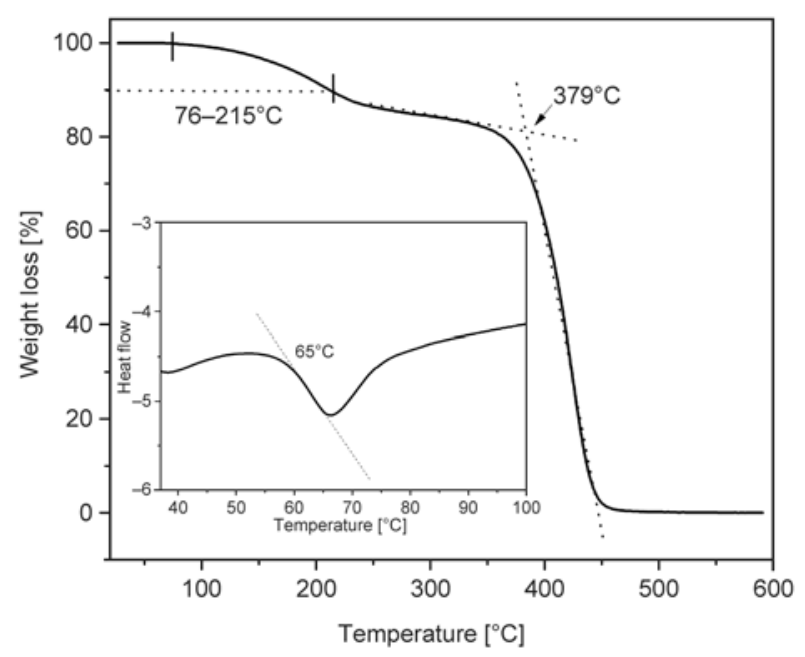

Figure 3. TGA / DSC thermogram of PS- $b$-MMA/MAA block copolymer. Heating rate $10^{\circ} \mathrm{C} / \mathrm{min}$

weight loss at $215^{\circ} \mathrm{C}$. This temperature range is attributed to water loss (dehydration) associated with functional groups ( $\mathrm{COOH}$ groups) of hydrophilic segment PMAA. The second weight change is attributable to decomposition of material from 330 $379^{\circ} \mathrm{C}$. The resulting material has an extrapolated thermal decomposition temperature (TDT) of approximately $379^{\circ} \mathrm{C}$, when decomposition of backbone chain occurs.

$T_{\mathrm{g}}$ value reflects the change in the DSC slope curve after the second heating run. The result show that the copolymers have a low glass transition temperature in relation to previously studied systems [25]. This behavior is attributed to the moisture entrapped in the sample, because $-\mathrm{COOH}$ functional groups, in which moisture would be acting as a plasticizer, decrease the $T_{\mathrm{g}}$. It is known that $T_{\mathrm{g}}$ depends very much on the moisture content. Therefore, moisture is an efficient plasticizer.

\subsection{Optical properties}

The UV-Vis absorption and fluorescence emission spectra were recorded at room temperature. UV-Vis spectrum of dilute PS- $b$-MMA/MAA copolymers solutions (Figure 4) exhibit four characteristic bands at 220,261, 270 and $293 \mathrm{~nm}$. The band near at $220 \mathrm{~nm}$ is related to the cut-off of tetrahydrofuran used as solvent. An intense absorption at $261 \mathrm{~nm}$ could be attributed to the $\pi-\pi^{*}$ transition due to electron delocalization in the aromatic ring (intermolecular transfer change). At $270 \mathrm{~nm}$, the band of medium intensity may be related to the non-conjugated $\pi$-systems of the main chain ester pendant groups. Finally, the small band at $293 \mathrm{~nm}$ is related to overlapping of atomic orbitals produced from the inter-molecular interaction between aromatic rings. The luminescence spectra of the copolymer are also shown in Figure 4 (left side). When the compound is excited with a wavelength of $320 \mathrm{~nm}$, the sample presents blue emission with a peak maximum at $337 \mathrm{~nm}$. This color is related to the poorly conjugated system of the copolymer that can be only attributed to the aromatic ring and the double bond ester groups.

Finally, copolymer solution used in optical studies was highly transparent, which can be attributed to 


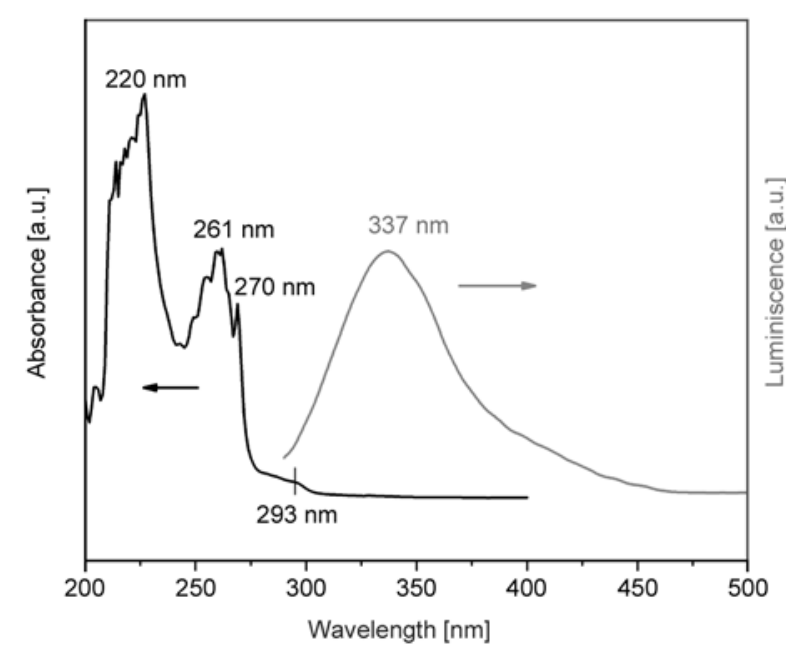

Figure 4. UV-Vis spectra (right) and photoluminescence spectrum of PS- $b$-MMA/MAA block copolymer films (left)

the lower fraction of PMAA segment owing to the reduced chain packing resulting from the presence of special interactions between these chains.

\subsection{Cyclic voltammetry}

The sample electrochemical behaviors were tested under potential range from -1.0 to $+1.0 \mathrm{~V}$ and from -1.5 to $1.5 \mathrm{~V}$ (scan rate $100 \mathrm{mV} / \mathrm{s}$ ). The block copolymer cyclic voltammetry $(\mathrm{CV})$ characterization is shown in Figure 5. In these voltammograms, it is observed that the block copolymer did not exhibit oxidation-reduction process under $\mathrm{CV}$ analysis conditions. In all cases an oxidation small wave was observed; this could correspond to the peroxide oxidation generated in the oxygen reduction, which was observed at low potential (electrocatalysis) (approximately from -0.7 to $-0.5 \mathrm{~V}$ ). The range of electrochemical inertia can be extended to $-1.0 \mathrm{~V}$. The oxidation-reduction process obtained corresponds to the oxygen reduction and peroxide oxidation. A redox process was not observed for the copolymer under tested conditions. This copolymer shows electrochemical stability and thus provides an ideal platform for fabricating novel functional nanostructured materials for potential applications in advanced technologies such as optical coatings and information storage.

\subsection{Morphological analysis}

Morphological characterizations of polymer films were realized by AFM and SEM. The samples were prepared in films without further processing. The copolymer was dissolved in THF $(0.5 \mathrm{mg} / \mathrm{mL})$ and
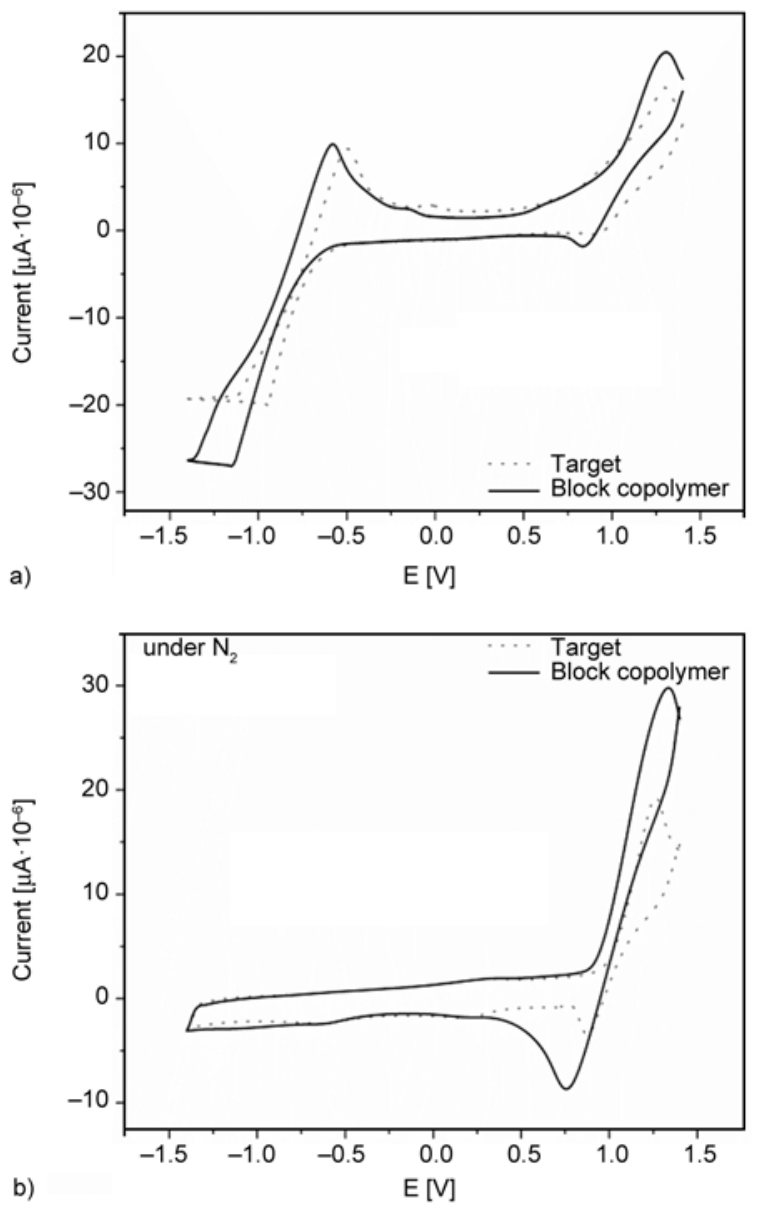

Figure 5. Cyclic voltammetric response of glassy carbon electrode cycled in a solution containing PS- $b$ MMA/MAA block copolymer and target. Scan rate: a) $100 \mathrm{mV} / \mathrm{s}$ and b) under nitrogen.

deposited over silicon wafer $\left(\mathrm{Si}_{100} / \mathrm{SiO}_{2}\right)$ using spin coating. Typical SEM microphotographs of PS- $b$ MMA/MAA block copolymer at different concentration are shown in Figure 6. SEM images give additional information about size and dispersion of block copolymer at $0.5 \mathrm{mg} / \mathrm{mL}$ in THF, which form a porous-structure, see Figure 6a. The microphase separation between both domains occurs due to the different block and block copolymer lengths, the structure tend to adopt a spherical shape via nucleation growth manner; also, aggregation arises with increasing concentration $(1.0 \mathrm{mg} / \mathrm{mL})$, see Figure $6 \mathrm{~b}$. SEM images show that the block copolymer form micelles spherical aggregates in THF/MeOH (drops). The micelles can assume different forms depending on solvent-block interactions and block sizes [26]. The particles size dispersion measure by DLS was relatively narrow $(\fallingdotseq=0.347)$ with an effective particle diameter of $32 \mathrm{~nm}(0.5 \mathrm{mg} / \mathrm{mL})$. As the block copolymer concentration increased $(1.0 \mathrm{mg} / \mathrm{mL})$ 


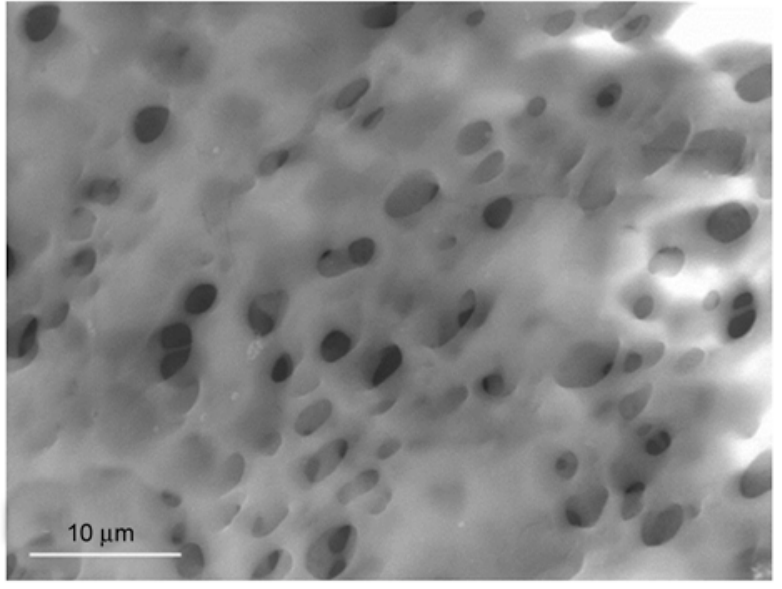

a)

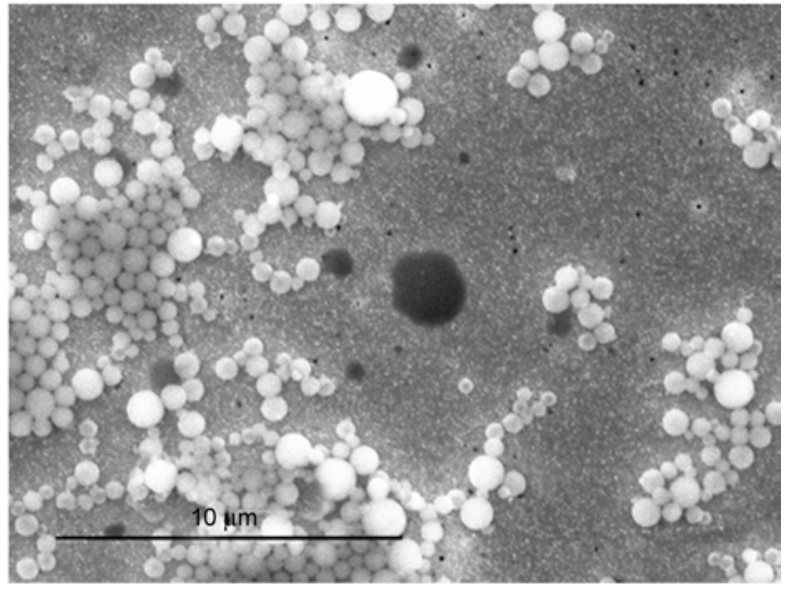

b)

Figure 6. SEM microphotographs obtained from spin-coated films of PS- $b$-MMA/MAA block copolymer a) $0.5 \mathrm{mg} / \mathrm{mL}$ and b) $1.0 \mathrm{mg} / \mathrm{mL}$

large spherical aggregates were detected with a narrow size distribution $(\nexists=0.352)$ and an effective diameter of $120.2 \mathrm{~nm}$. The particle size range showed that the micelles tended to self-assemble into much larger micellar aggregates that finally predominate.

\subsection{Characterization of the polymeric films}

The copolymer was dissolved in THF and spincoated on $\mathrm{Si}_{(100)} / \mathrm{SiO}_{2}$ wafers. Silicon wafers of $0.5 \times 0.5 \mathrm{~cm}$ were used for polymer films fabrication by copolymer dissolution in THF and spin-coating (360 rpm/18 s and $1480 \mathrm{rpm} / 60 \mathrm{~s}$ ). Two types of films were prepared: The first series was subjected to annealing $\left(120^{\circ} \mathrm{C}\right.$ for $\left.2 \mathrm{~h}\right)$ and the second series films were annealed and exposed to UV light at $254 \mathrm{~nm}$ for 2, 4, 6, and $8 \mathrm{~h}$. Both series of films were studied with techniques such as VHRE for film thickness measures, Raman spectroscopy for crystallinity degree, AFM and SEM for the effect of UV irradiation on the microstructure and pore diameter size. The annealing temperature $\left(120^{\circ} \mathrm{C}\right)$ is related to the intrinsic properties of the copolymer $\left(T_{\mathrm{g}}=65^{\circ} \mathrm{C}\right.$, Figure 3$)$. Beyond this temperature, localized bond movements favor changes in order and homogeneity at the surface level. Radiation with wavelength of $254 \mathrm{~nm}$ is related to the optical properties of the material and a possible $\pi-\pi^{*}$ transition. The low thickness of the polymer films and good homogeneity produced by spin-coating did not change the optical properties of the silicon wafer ( $n=$ 1.46). The refractive indexes of poly(methylacrylate) and polystyrene are $n_{\mathrm{PMA}}=1.4793$ and $n_{\mathrm{PS}}=1.5894$, respectively. Thus, average refractive index of the film was $n=1.465$. The results for thin film thickness obtained by VHRE are shown in Table 1. Five samples were annealed at $120^{\circ} \mathrm{C} / 2 \mathrm{~h}$, and four of the films were irradiated for $2,4,6$, and $8 \mathrm{~h}$ at $254 \mathrm{~nm}$.

\subsection{Studies of the polymeric films by Raman spectroscopy}

According to the results, Raman spectrum shown in the Figure $7 \mathrm{a}$ is totally different to those presented in Figure 2, this behavior could be related to the annealing process effected on the films, producing a change in the functional group arrangement that form the copolymers and therefore a restructuration in the porous layer.

When the thin films were annealed at $120^{\circ} \mathrm{C}(2 \mathrm{~h})$ above the glass transition temperature $\left(65^{\circ} \mathrm{C}\right)$, the

Table 1. Thin films thickness obtained using VHRE

\begin{tabular}{|c|c|c|c|}
\hline Samples & $\begin{array}{l}\text { Thickness of the thin films } \\
\text { [nm] }\end{array}$ & $\begin{array}{c}\text { Pore diameter } \\
{[\mathrm{nm}]}\end{array}$ & $\begin{array}{l}\text { Pore depth } \\
\text { [nm] }\end{array}$ \\
\hline Annealed at $120^{\circ} \mathrm{C}$ for $2 \mathrm{~h}$ & 27.4 & 791 & 25 \\
\hline \multicolumn{4}{|c|}{ Annealed at $120^{\circ} \mathrm{C}$ and UV irradiated at $254 \mathrm{~nm}$. } \\
\hline $2 \mathrm{~h}$ under irradiation & 29.1 & 1149 & 21 \\
\hline $4 \mathrm{~h}$ under irradiation & 26.2 & 1136 & 25 \\
\hline $6 \mathrm{~h}$ under irradiation & 27.4 & 1099 & 25 \\
\hline $8 \mathrm{~h}$ under irradiation & 28.2 & 1138 & 25 \\
\hline
\end{tabular}



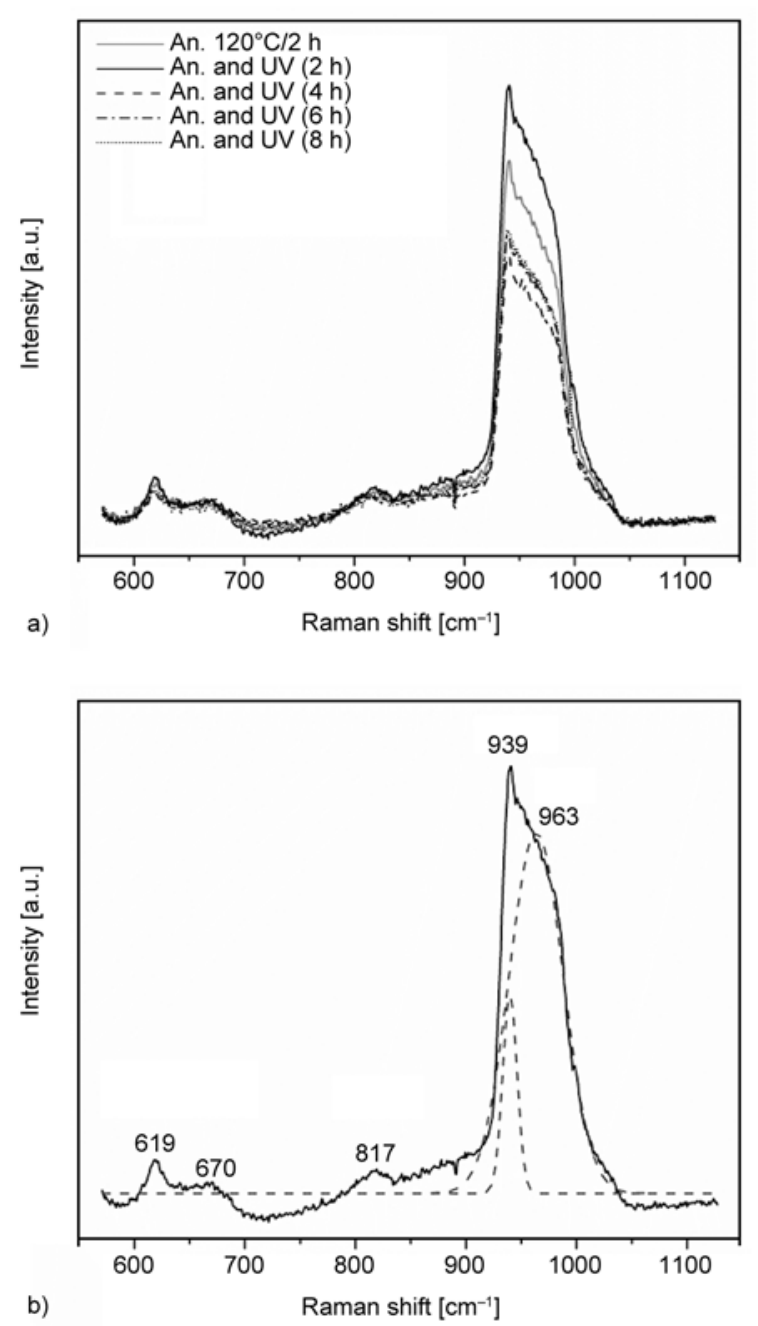

Figure 7. Raman shifts of thin films as a function of annealing and irradiation time, and b) spectral band deconvolution analysis of one sample annealed at $120^{\circ} \mathrm{C}$ and irradiated at $254 \mathrm{~nm}$ for $2 \mathrm{~h}$

Raman spectrum showed five bands at 619,670 , 817,939 , and $963 \mathrm{~cm}^{-1}$ representative of the aromatic group. These values were obtained from the band deconvolution analysis (see Figure 7b). Thus, bands near $619-817 \mathrm{~cm}^{-1}$ are low intensity, possibly related to the aromatic ring $\mathrm{C}-\mathrm{H}$ out of plane. The high-intensity band with overlap of two vibrations at 939 and $963 \mathrm{~cm}^{-1}$ respectively, were assigned to aromatic ring $\mathrm{C}-\mathrm{C}$ and $\mathrm{C}-\mathrm{O}$ stretching of the copolymer pendant ester group.

\subsection{Measurements of contact angle on the polymeric film}

Two films were prepared, the first was not subjected to annealing and the second film was annealed $\left(120^{\circ} \mathrm{C}\right)$ and exposed to UV light at $254 \mathrm{~nm}$ for $2 \mathrm{~h}$. Even in an almost perfectly smooth surface obtained by spin coating, a drop will assume a wide spectrum of contact angles between the highest (advancing) contact angle, $\theta_{\mathrm{A}}$, and the lowest (receding) contact angle, $\theta_{\mathrm{R}}$. The roughness effect on the contact angle was determined from the area project $\left(25 \mu \mathrm{m}^{2}\right)$ and real area $\left(28 \mu \mathrm{m}^{2}\right)$ data obtained by AFM. When the thin films were annealed at $120^{\circ} \mathrm{C}(2 \mathrm{~h})$ above the glass transition temperature $\left(65^{\circ} \mathrm{C}\right)$, the contact angle value of the film was approximately $80^{\circ}$ (corrected from AFM data) and without annealing the contact angle value of the film was $72^{\circ}$; according with these results, is possible to conclude that the film increases the surface hydrophilicity. This behavior was attributed to the annealing process that produces a change in the order and, also, in the functional group arrangement; therefore, porous film will form. This provides some information regarding the hydrogen bonding interactions between carboxylic acids and carbonyl ester groups on the surface of prepared films, where these functional groups increase surface hydrophilicity. The increase in the contact angle value suggests additional interactions that influence the wettability of the film [27].

\subsection{Morphological analysis by AFM and SEM}

Figure 8 shows the AFM/SEM image of the polymer films. All the thin films were annealed at $120^{\circ} \mathrm{C}$; however, only one was taken as base $(2 \mathrm{~h})$ (Figure 8a) and four were irradiated with UV light of $245 \mathrm{~nm}$ for 2, 4, 6, and $8 \mathrm{~h}$ (Figure 8b-8c). The AFM reveals that the surface monolayer has circular pores or individual cavities that are directly connected. The sample that was annealed at $120^{\circ} \mathrm{C}$ for $2 \mathrm{~h}$ displays pore dimensions of $\sim 791 \mathrm{~nm}$ (diameter) and $\sim 25 \mathrm{~nm}$ (depth) (Figure 8a). This behavior was mainly modified by UV irradiation at different time of exposition (Figure 8b-8c). Accordingly, samples that were irradiated at 2, 4, 6, and 8 hours showed an increase in pore diameter size compared to the sample base without radiation. Their values were $1149,1136,1099$, and $1138 \mathrm{~nm}$, respectively. All the samples, except the one irradiated for 2 hours $(21 \mathrm{~nm})$, displayed pore depth of $25 \mathrm{~nm}$. The last thin film ( $8 \mathrm{~h}$, UV irradiation) showed a possible fluctuation of density that affects the clarity of the image, producing a distortion of the porous-structure real topography. Moreover, SEM results show that the diameter pore size of these sample film was around $\sim 1000 \mathrm{~nm}$. Notably, irradiation time does not strongly affect particle diameter pore size. On the other hand, if it is compare samples with similar 

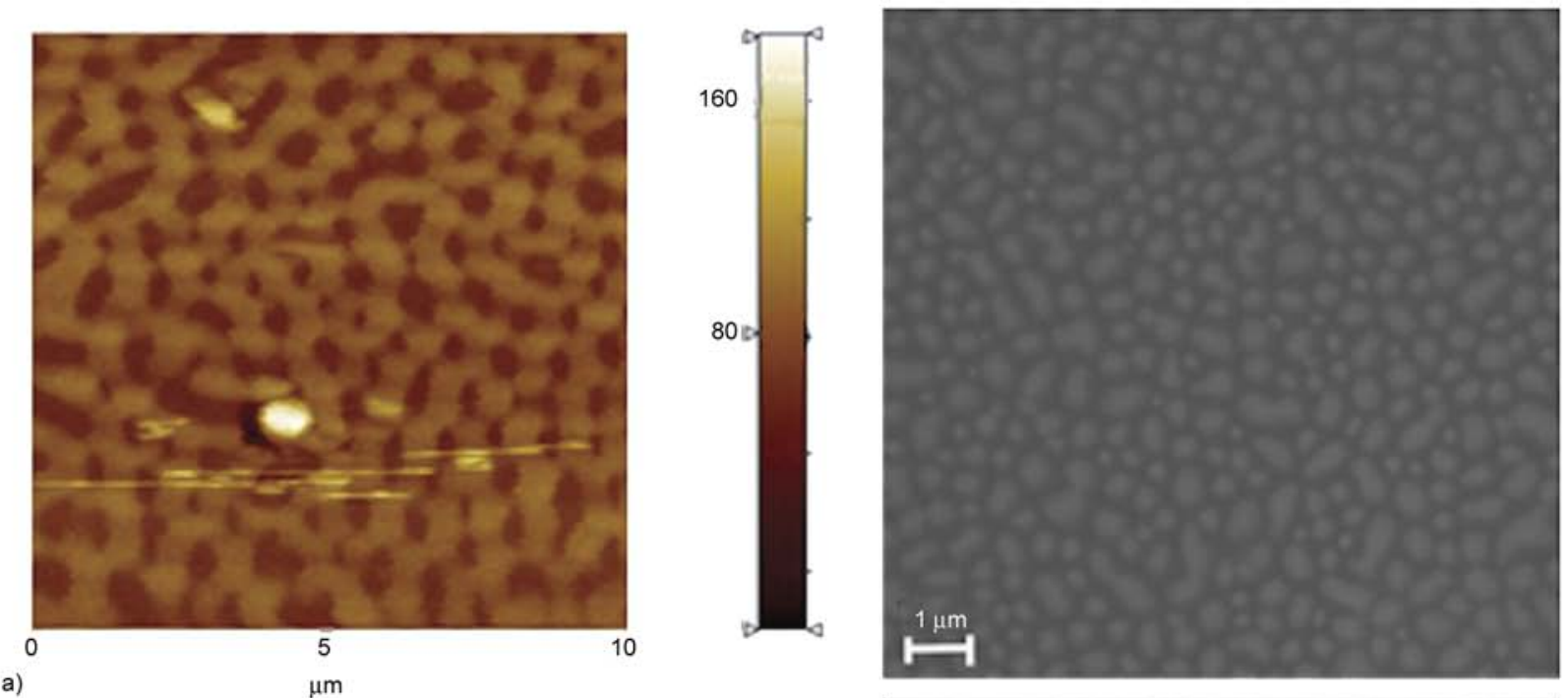

a)

$\mu \mathrm{m}$
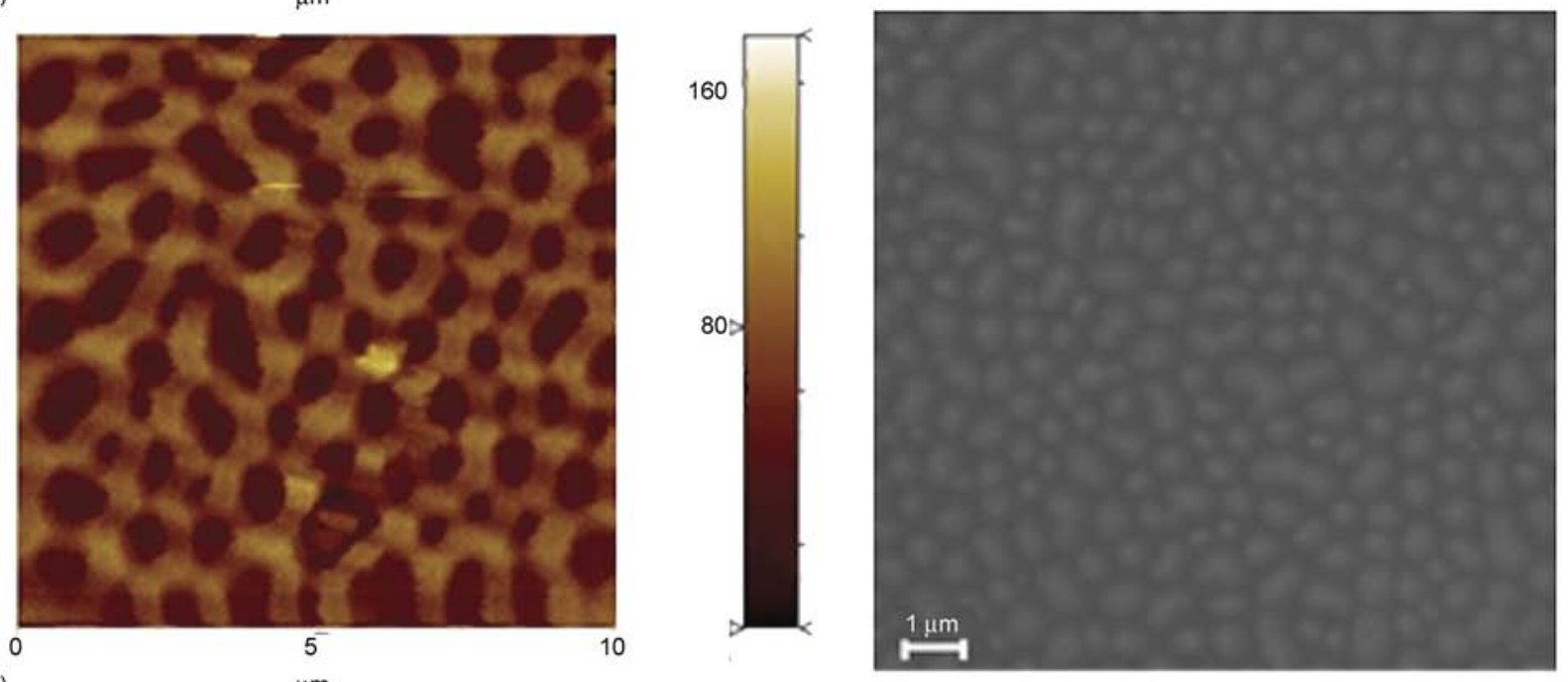

b)

$\mu \mathrm{m}$
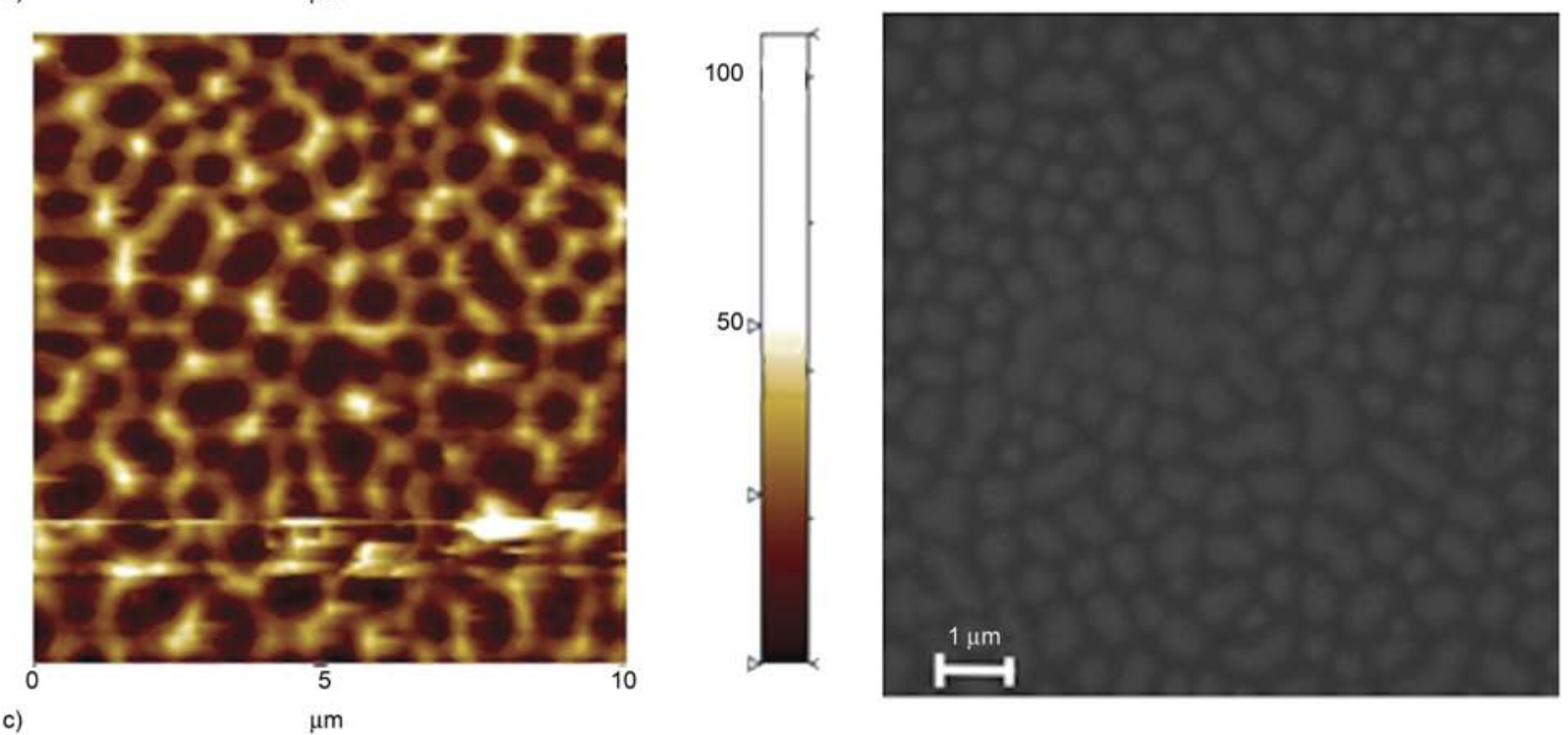

Figure 8. AFM and SEM of copolymers obtained through annealing at $120^{\circ} \mathrm{C}(2 \mathrm{~h})$ and irradiation at $254 \mathrm{~nm}$ : a) annealing at $120^{\circ} \mathrm{C}, \mathrm{b}$ ) annealing at $120^{\circ} \mathrm{C}$ and $4 \mathrm{~h}$ irradiation; c) annealing at $120^{\circ} \mathrm{C}$ and $6 \mathrm{~h}$ irradiation

thickness at $0,2,4$, and $6 \mathrm{~h}$ of irradiation, it is possible to conclude that non-irradiated samples possess smaller pore diameter size that the UV-irradi- ated samples and these last exhibited approximately the same pore diameter size, greater than the sample film base. 
For a high molecular weight block copolymer, as the used in this study, carboxylic acid end-groups allows the generation of polar segments, increasing macromolecular chains amphiphilic character. They must exhibit chemical and physical star-like structures due to macromolecule polar end-chain insolubility [28].

\section{Conclusions}

Thin films based on a well-controlled structure of a single amphiphilic block copolymer with relatively low dispersity $(\nexists<1.28)$ were obtained by spincoating. The films exhibited UV absorption in the blue region of the spectrum and high transparency that can be attributed to a smaller fraction of PMAA, owing to reduced chain packing from special interactions between these chains. Electrochemical analysis did not show oxide-reduction process under these conditions. The curves indicate no electro-activity. This electrochemical stability provides an ideal platform for fabricating novel functional nanostructured materials, for potential applications in advanced technologies such as optical coatings and information storage. The films exhibit thermal stability because to their high extrapolated thermal decomposition temperature $\left(\mathrm{TDT}=379^{\circ} \mathrm{C}\right)$. The films annealing and exposed to UV light showed a porous structure based on this self-assembled amphiphilic block copolymer. AFM images of the film show a uniform rough surface morphology due to microphase separation of the block copolymer. This behavior was attributed to a self-assembling effect of PMAA in the microstructure.

Finally, it can be concluded that when the copolymer is annealed over the glass transition temperature, the functional groups of the compound are rearranged. Therefore, different vibrational groups in the Raman spectroscopy were observed, particularly the aromatic group that formed the copolymer. AFM reveals that the nanopores or individual cavities are directly open to the surface. The pore dimensions are controlled by UV irradiation on the sample. Thus, a decrease in pore diameter was observed without UV irradiation and the pore depth is directly related to film thickness.

\section{Acknowledgements}

The authors acknowledge the financial support of this work by Fondo Nacional de Investigación Científica y Tecnológica, FONDECYT Grant 1110836 and 11121281, UTEM Grant, and the WCU Program funded by MEST (R3110026). Also, Mr. Sarabia acknowledges the Master studies grant give by CONICYT.

\section{References}

[1] Wang D., Wang X.: Amphiphilic azo polymers: Molecular engineering, self-assembly and photoresponsive properties. Progress in Polymer Science, 38, 271-301 (2013). DOI: $10.1016 /$ j.progpolymsci.2012.07.003

[2] Lee L-H., Chen W-C.: High-refractive-index thin films prepared from trialkoxysilane-capped poly(methyl methacrylate)-titania materials. Chemistry of Materials, 13, 1137-1142 (2001). DOI: $10.1021 / \mathrm{cm} 000937 \mathrm{z}$

[3] Karthaus O., Adachi C., Kurimura S., Oyamada T.: Electroluminescence from self-organized 'microdomes'. Applied Physics Letters, 84, 4696-4698 (2004). DOI: $10.1063 / 1.1760592$

[4] Chari K., Lander C. W., Sudol R. J.: Anamorphic microlens arrays based on breath-figure template with adaptive surface reconstruction. Applied Physics Letters, 92, 111916/1-111916/4 (2008).

DOI: $10.1063 / 1.2901027$

[5] Chaudhuri J. B., Davidson M. G., Ellis M. J., Jones M. D., Wu X. J.: Fabrication of honeycomb-structured poly(DL-lactide) and poly[(DL-lactide)-co-glycolide)] films and their use as scaffolds for osteoblast-like cell culture. Macromolecular Symposia, 272, 52-57 (2008). DOI: $10.1002 /$ masy.200851206

[6] Xu X., Zhuang J., Wang X.: $\mathrm{SnO}_{2}$ quantum dots and quantum wires: Controllable synthesis, self-assembled 2D architectures, and gas-sensing properties. Journal of the American Chemical Society, 130, 12527-12535 (2008).

DOI: $10.1021 / \mathrm{ja} 8040527$

[7] Hamley I. W.: Ordering in thin films of block copolymers: Fundamentals to potential applications. Progress in Polymer Science, 34, 1161-1210 (2009). DOI: $10.1016 /$ j.progpolymsci.2009.06.003

[8] Xia Y., Kim E., Zhao X-M., Rogers J. A., Prentiss M., Whitesides G. M.: Complex optical surfaces formed by replica molding against elastomeric masters. Science, 273, 347-349 (1996).

DOI: $10.1126 /$ science.273.5273.347

[9] Kim E., Xia Y., Whitesides G. M.: Polymer microstructures formed by moulding in capillaries. Nature, 376, 581-584 (1995). DOI: $10.1038 / 376581 \mathrm{a} 0$ 
[10] Yamaguchi T., Inagawa T., Nakasumi H., Irie S., Irie M.: Photoinduced pitch changes in chiral nematic liquid crystals formed by doping with chiral diarylethene. Journal of Materials Chemistry, 11, 2453-2458 (2001). DOI: $10.1039 / \mathrm{B} 103925 \mathrm{~N}$

[11] Luo C., Xing R., Han Y.: Ordered pattern formation from dewetting of polymer thin film with surface disturbance by capillary force lithography. Surface Science, 552, 139-148 (2004).

DOI: $10.1016 /$ j.susc.2004.01.042

[12] Widawski G., Rawiso M., François B.: Self-organized honeycomb morphology of star-polymer polystyrene films. Nature, 369, 387-389 (1994).

DOI: $10.1038 / 369387 \mathrm{a} 0$

[13] Mitov Z., Kumacheva E.: Convection-induced patterns in phase-separating polymeric fluids. Physical Review Letters, 81, 3427-3430 (1998). DOI: 10.1103/PhysRevLett.81.3427

[14] Affrossman S., Jerome R., O’Neill S. A., Schmitt T., Stamm M.: Surface structure of thin film blends of polystyrene and poly( $n$-butyl methacrylate). Colloid and Polymer Science, 278, 993-999 (2000). DOI: $10.1007 / \mathrm{s} 003960000358$

[15] Sun P., Zhang Y., Shi L., Gan Z.: Thermosensitive nanoparticles self-assembled from PCL- $b$-PEO- $b$ PNIPAAm triblock copolymers and their potential for controlled drug release. Macromolecular Bioscience, 10, 621-631 (2010). DOI: 10.1002/mabi.200900434

[16] Guarini K. W., Black C. T., Yeung S. H. I.: Optimization of diblock copolymer thin film self assembly. Advanced Materials, 14, 1290-1294 (2002). DOI: $10.1002 / 1521-4095(20020916) 14: 18<1290:: A I D-$ ADMA1290>3.0.CO;2-N

[17] Yang S. Y., Ryu I., Kim H. Y., Kim J. K., Jang S. K., Russell T. P.: Nanoporous membranes with ultrahigh selectivity and flux for the filtration of viruses. Advanced Materials, 18, 709-712 (2006).

DOI: 10.1002/adma.200501500

[18] Phillip W. A., O’Neill B., Rodwogin M., Hillmyer M. A., Cussler E. L.: Self-assembled block copolymer thin films as water filtration membranes. ACS Applied Materials and Interfaces, 2, 847-853 (2010).

DOI: $10.1021 / \mathrm{am} 900882 \mathrm{t}$
[19] Phillip W. A., Hillmyer M. A., Cussler E. L.: Cylinder orientation mechanism in block copolymer thin films upon solvent evaporation. Macromolecules, 43, 77637770 (2010). DOI: $10.1021 / \mathrm{ma} 1012946$

[20] Jackson E. A., Hillmyer M. A.: Nanoporous membranes derived from block copolymers: From drug delivery to water filtration. ACS Nano, 4, 3548-3553 (2010). DOI: $10.1021 / \mathrm{nn} 1014006$

[21] Zhao H., Gu W., Sterner E., Russell T. P., Coughlin E. B., Theato P.: Highly ordered nanoporous thin films from photocleavable block copolymers. Macromolecules, 44, 6433-6440 (2011).

DOI: $10.1021 / \mathrm{ma} 201416 \mathrm{~b}$

[22] Wang Y., He C., Xing W., Li F., Tong L., Chen Z., Liao X., Steinhart M.: Nanoporous metal membranes with bicontinuous morphology from recyclable blockcopolymer templates. Advanced Materials, 22, 20682072 (2010).

DOI: $10.1002 /$ adma.200903655

[23] Cheng J. Y., Ross C. A., Smith H. I., Thomas E. L.: Templated self-assembly of block copolymers: Topdown helps bottom-up. Advanced Materials, 18, 25052521 (2006). DOI: $10.1002 /$ adma.200502651

[24] del C. Pizarro G.: Jeria-Orell M., Marambio O. G., Olea A. F., Valdés D. T., Geckeler K. E.: Synthesis of functional poly(styrene)-block-(methyl methacrylate/ methacrylic acid) by homogeneous reverse atom transfer radical polymerization: Spherical nanoparticles, thermal behavior, self-aggregation, and morphological properties. Journal Applied Polymer Science, 129, 2076-2085 (2013).

DOI: $10.1002 / a p p .38923$

[25] Wypych G.: Handbook of polymers. ChemTec Publishing, Toronto (2012).

[26] Israelachvili J. N.: Intermolecular and surface forces. Academic Press, Waltham (2011).

[27] Tamada Y., Ikada Y.: Fibroblast growth on polymer surfaces and biosynthesis of collagen. Journal of Biomedical Materials Research, 28, 783-789 (1994). DOI: $10.1002 / \mathrm{jbm} .820280705$

[28] Zhong X. F., Eisenberg A.: Aggregation and critical micellization behavior of carboxylate-terminated monochelic polystyrene. Macromolecules, 27, 1751-1758 (1994).

DOI: $10.1021 / \mathrm{ma} 00085 \mathrm{a} 013$ 